\title{
Poczekalnia
}

\section{w reżyserii Krystiana Lupy okiem francuskiej krytyki teatralnej}

Krystian Lupa, okrzyknięty przez francuską krytykę l'enfant terrible teatru europejskiego, zalicza się, obok Jerzego Grotowskiego, Tadeusza Kantora i Krzysztofa Warlikowskiego, do najbardziej cenionych polskich reżyserów w Paryżu. Jego najgłośniejszym francuskim spektaklem jest, wystawiana od 7 stycznia do 4 lutego 2011 roku w paryskim Théâtre de la Colline, Poczekalnia (La Salle d'attente), zrealizowana we współpracy ze szwajcarskim Théâtre de Vidy.

Tym razem reżyser zabrał widzów do opuszczonej poczekalni przestrzeni, gdzie niczym w Schulzowskim Sanatorium Pod Klepsydrą czas zdaje się być zawieszony, odsłaniając atrofię i rozkład świata. Panuje w nim wszechobecne zniszczenie i brzydota. "Ja chyba mam schizofrenię, bo jestem taki brzydki" - powie Żul, jeden z bohaterów. Obłęd staje się integralną częścią dworcowej poczekalni, która jest tak naprawdę wielkim wysypiskiem śmieci. Nie chodzi tu tylko o porzucone torebki foliowe i zużyte opakowania. Mowa przede wszystkim o bohaterach - o tych, którzy przestali być przydatni, przeobrazili się w śmieci. Lupa ukazuje skrajne uprzedmiotowienie, które w ostateczności zmienia człowieka w odpadek. Ale tytułowa poczekalnia nie jest tylko śmietnikiem. To azyl, squat, w którym odrzuceni mogą schronić się przed przerażającą rzeczywistością. Tak pisze o nich francuski krytyk Hugues Le Tanner:

Bohaterem Poczekalni jest margines społeczny: włóczędzy, narkomani, ci, którzy na początku swojej drogi zostali odrzuceni przez społeczeństwo. Jedyne, co mogą, to snuć marzenia, czekając na cud, który nie nadejdzie.

* UniwersytetŁódzki,Wydział Filologiczny, Katedra Literaturyi Tradycji Romantyzmu. 
Poczekalnia skupia pasażerów martwego pociągu, zatrzymanego pośród wiecznej nocy gdzieś na stacji kolejowej na kilka godzin¹.

W pamięć zapada jedna z pierwszych scen, gdy nadpobudliwa Anna mówi, że wszystkie drapacze chmur $\mathrm{w}$ jej mieście zostały postawione przez Zelmera - tego samego, który budował piece krematoryjne w Auschwitz. Nikomu to jednak nie przeszkadza. Zbrodnie nie zostały i nie mogą być rozliczone, bo nie obchodzi to sytych, którzy żyją nad przestrzenią poczekalni. Tymczasem poczekalnia przeistacza się $\mathrm{w}$ miejsce ostatecznego rozliczenia, które gromadzi wszystkie grzechy współczesnego społeczeństwa. Co ty dziś wyrzucisz, jutro zostanie odgrzebane przez bezdomnych i narkomanów. W wywiadzie udzielonym Théâtre de Vidy reżyser powie:

Od dawna interesuję się penetracją tej grupy ludzi, których nazywamy wyrzuconymi. To jest niesamowita kondycja, której wciąż poświęcamy za mało uwagi. [...] Wydaje mi się, że wyrzuceni przez naszą kulturę mają jakąś wiadomość dla nas i powinnyśmy jej wysłuchać².

Dlatego to właśnie im da głos w swoim spektaklu. Głos rozdygotany, niekiedy wręcz rozerwany na strzępy słów i nie zawsze zrozumiałych zdań. Jednym z głównych problemów spektaklu jest atrofia języka, która uniemożliwia bohaterom nawiązanie porozumienia.

Gdy na ekranie widz ujrzy projekcję przedstawiającą parę kochanków - wrażliwego muzyka i jego zapobiegliwą dziewczynę - nie będzie w stanie zogniskować jakiegokolwiek komunikatu, ponieważ ich kwestie nakładają się jedna na drugą. Można odnieść wrażenie, że bohaterowie próbują zdominować się słowami, wyprzeć i stłamsić to, co chce powiedzieć druga strona. Oprócz kwestii zaburzonej komunikacji dla Lupy fundamentalnym problemem okazuje się też rozpad języka. Bohaterowie tworzą komunikaty, które na pewnym etapie ulegają całkowitej atrofii, zmieniając się $\mathrm{w}$ potok pozbawionych sensu wulgaryzmów. Słowa nieustannie powtarzane, wrzucane $\mathrm{w}$ monotonny rytm delirycznych majaczeń tracą swoje znaczenie, stają się obce i martwe.

$\mathrm{W}$ ten sposób ukazany jest proces, który doprowadza do całkowitej alienacji bohaterów. Sceny wspólnego wstrzykiwania heroiny przez kochanków przypominają akt miłosny - są nerwowe, namiętne, sugerują błogie rozluźnienie - z tą jednak różnicą, że nie zapewniają postaciom żadnej bliskości. Każdy osobno przeżywa swój „haj”. Nawet, kiedy zwierzają się sobie, mówiąc o miłości i przywiązaniu, pozostają niewysłuchani. Widz odnosi wrażenie, że wszystkie dialogi są groteskową mistyfikacją, a ze sceny można usłyszeć tylko niekończący się potok monologów. Monologów, które

1 H. Le Tanner, "Salle d'attente" de Krystian Lupa, superbe et émouvant [online], przeł. Mateusz Grabowski, Paryż 2012. http://www.lesinrocks.com/2012/01/11/arts-scenes/scenes/ salle-dattente-de-krystian-lupa-superbe-et-emouvant-114441/ [dostęp 29.06.2014].

2 Interview de Krystian Lupa (Théâtre de Vidy). Wywiad udostępniony online. Tryb dostepu: https://www.youtube.com/watch?v=wK39nEPGnOA [dostęp: 29.06.2014]. 
w dużej części są improwizowane. To właśnie one mają budować autentyzm postaci. Jak zauważa Jean Pierre Thibaudat:

Lupa mówi o podstawach swojej pracy z „improwizacją” (która nigdy się nie kończy, nawet podczas spektaklu), nazywając ją „monologiem wewnętrznym". Ma ona decydujące znaczenie w akcie pracy nad rolą. Jest oczywiste, że przez improwizację Lupa ma na myśli zawłaszczenie, pochłonięcie kreacji przez aktora ${ }^{3}$.

Dla Lupy aktor musi stworzyć kreację ze szczątków tego, co wyparte, odrzucone, zapomniane:

Najbardziej paradoksalne w pracy nad Poczekalnia jest to, że te obszary życia, tak niebezpieczne, negatywne, związane ze smutkiem, mogą inspirować wyobraźnię, pozwolić znaleźć aktorom formę wolności i szczęścia ${ }^{4}$.

Spotkanie w Poczekalni nabiera więc charakteru doświadczenia wyzwalającego i oczyszczającego. Według Davida Larrego, przedstawienie Lupy jest „anarchicznym manifestem przeciwko sytym i zadowolonym, buntem prawdziwie wolnych przeciwko zniewolonym" ${ }^{\prime \prime}$. Jednak nawet jeżeli dochodzi do wielkiej demistyfikacji i zamiany ról, to spektakl nie przestaje być bolesną wiwisekcją dysfunkcyjnej rzeczywistości.

Poprzez symultaniczne prowadzenie akcji na ekranie i scenie można dostrzec subtelności, które umykałyby w tradycyjnych realizacjach. Widać, jak postaci próbują ustanowić jakąkolwiek bliższą więź oraz jak wszystkie ich starania skazane są na porażkę. Jedyną możliwością nawiązania kontaktu przez reanimację języka staje się wspólne śpiewanie piosenek. Scena śpiewu Micke'a i Sanny jest jednym z najbardziej intymnych i delikatnych fragmentów spektaklu.

To, co jednak najbardziej zadziwia, to konsekwencja prowadzonej akcji. Cały spektakl utrzymany jest w powolnym, delirycznym rytmie. Choć miejscami jest to męczące dla widza, to jednak nie sposób odmówić dziełu autentyczności. Lupa nie chce mówić o wykluczonych w sposób efekciarski. Zależy mu na prawdzie, nawet jeżeli wymaga ona od widza bardzo dużego emocjonalnego wysiłku. Spektakl wręcz wysysa, miażdży. Nie ogląda się go dobrze. I taki prawdopodobnie był cel. Dzięki temu Poczekalnia nie jest przeglądem zużytych sloganów, a bolesnym zapisem wycinka rzeczywistości.

3 J. P. Thibaudat, "La Salle d' attente” de Krystian Lupa, de spectacle majeur [online], przeł. Mateusz Grabowski, Paryż 2011. http://blogs.rue89.nouvelobs.com/balagan/2011/06/22/lasalle-d-attente-de-krystian-lupa-un-spectacle-majeur-210220 [dostęp: 29.06.2014].

4 H. Le Tanner, ," Salle d'attente"...

5 D. Larry, Critique: Salle d'attente (Lars Norén/Krystian Lupa) [online], przeł. Mateusz Grabowski, Paryż 2011. http://www.aupoulailler.com/article-critique-salle-d-attente-larsnoren-krystian-lupa-96886925-html/ [dostęp: 29.06.2014]. 
W ostatecznym rozrachunku jest to spektakl także o artystach, ludziach szczególnie wrażliwych, którzy nie wytrzymali parcia rzeczywistości. Wydaje się, że reżyser pozostawił swoim aktorom bardzo dużo swobody, dzięki czemu wspólnie stworzyli głęboko prawdziwy tekst. Widowisko zyskało wymiar metateatralny. Jego istotę stanowi scena, w której jeden $\mathrm{z}$ bohaterów wstaje poniżony i zaćpany, mówiąc, że jest aktorem. Narkomania staje się bowiem metaforą aktorstwa, pokazanego przez Lupę nie jako dar, ale jako przekleństwo - to talent, który wyklucza, sprawia, że artysta przemienia się $\mathrm{w}$ obcego, bowiem nie pasuje do społeczeństwa. Francuscy aktorzy nie udają i nie utożsamiają się z rolą, ale łamią ją, by poprzez akt całkowitej deziluzji odkryć i pokazać prawdę. Dlatego w spektaklu można odnaleźć przekaz tak autentyczny, że aż bolesny. Słusznie zauważa Hugues Le Tanne, że jest to prowokacja wymierzona bezpośrednio w widzów - ma ich wybić ze skostniałej relacji aktor-widz, w której teatr staje się tylko przewidywalną grą iluzji. Teatr Lupy, jak podkreśla Thibaudat, jest namacalny i niemal organiczny. Jako taki ukazuje prawdziwe oblicze rzeczywistości. Rzeczywistości odczarowanej, odartej z iluzji i konwencji. Opuszczona poczekalnia jest wielką metaforą gruzowiska historii, na którym próbuje przetrwać współczesna elita artystyczna i intelektualna.

Fabienne Darge pisze o Lupie w paryskim „Le Monde” jako o "teatralnym potworze" ${ }^{\prime \prime}$ - genialnym demiurgu, któremu nie sposób odmówić przenikliwości, choć jego propozycje artystyczne są chwilami przerażające. Dla Tannera jego dzieła wpisują się w nurt teatru posttraumatycznego, którego reprezentantami byli Grotowski i Kantor. Bez wątpienia Krystian Lupa jest kontynuatorem ścieżki wyznaczonej przez dwóch wielkich poprzedników. I choć sam chętniej przyznaje się do inspiracji autorem Umarłej klasy niż Acropolis cum figuris, to jednak w jego twórczości spotykają się elementy teatru polskiego tak fascynujące zagraniczną publiczność. Poczekalnia jest jednym $\mathrm{z}$ wielkich teatralnych, postromantycznych manifestów, w którym kondycję bohaterów współtworzą rozmaite konteksty - od traumy po Holokauście po kryzys ideałów wolnego rynku.

\section{B I B LIO GR A F I A}

F. Darge, Nous, alcooliques, drougés, prostitutés, chômeurs... [online], przeł. M. Grabowski, Paryż 2012 [dostęp 29.06.2014]. http://www.lemonde.fr/ culture/article/2012/01/13/nous-alcooliques-drogues-prostitues-chomeurs_1629388_3246.html.

D. Larry, Critique: „Salle d'attente” (Lars Norén/KrystianLupa) [online], przeł. M. Grabowski, Paryż 2011 [dostęp: 29.06.2014]. http://www.aupoulailler.com/ article-critique-salle-d-attente-lars-noren-krystian-lupa-96886925-html.

6 F. Darge, Nous, alcooliques, drougés, prostitutés, chômeurs... [online], przeł. Mateusz Grabowski, Paryż 2012. http://www.lemonde.fr/culture/article/2012/01/13/nous-alcooliques-drogues-prostitues-chomeurs_1629388_3246.html [dostęp: 29.06.2014]. 
H. Tanner Le, "Salle d'attente"de KrystianLupa, superbe et émouvant [online], przeł. M. Grabowski, Paryż 2012 [dostęp: 29.06.2014]. http://www.lesinrocks.com/2012/01/11/arts-scenes/scenes/ salle-dattente-de-krystian-lupa-superbe-et-emouvant-114441/

J. P. Thibaudat, "La Salle d'attente"de Krystian Lupa, de spectacle majeur [online], przeł. M. Grabowski, Paryż 2011 [dostęp: 29.06.2014]. http://blogs.rue89.nouvelobs.com/balagan/2011/06/22/ la-salle-d-attente-de-krystian-lupa-un-spectacle-majeur-210220

\section{STRESZCZENIE}

Celem artykułu jest przybliżenie francuskich recenzji spektaklu Poczekalnia (La Salled'attente) w reżyserii Krystiana Lupy. Premiera spektaklu odbyła się 7 stycznia 2011 roku w paryskim Théâtre de la Colline. Widowisko od początku spotkało się z bardzo przychylnymi recenzjami, a sam reżyser został określony przez francuskich recenzentów teatralnym potworem, którego geniusz budzi podziw i przerażenie. Poczekalnia została odebrana przez francuską widownię jako postromantyczny manifest, w którym kondycja bohaterów utkana jest z rozmaitych kontekstów - od traumy po Holokauście po kryzys idei wolnego rynku.

\section{Słowa kluczowe}

recepcja, trauma, teatr postromantyczny, krytyka, wykluczenie

\section{S U M M A RY}

Poczekalnia by Krystian Lupain the eyes of French theatre critics

This article aims to discuss French reviews of the play Poczekalnia (La Salle d'attente) directed by Krystian Lupa. It premiered on 7 January 2011 at the Théâtre de la Colline in Paris to very favourable reviews, and the director himself was described by French reviewers as a "theatre monster" whose genius inspires admiration and awe. Poczekalniawas received by the French audience as a post-Romantic manifesto, in which the condition of the characters is woven from a variety of contexts - from the trauma of the Holocaust to the crisis of the idea of the free market.

\section{Keywords}

reception, trauma, post-Romantic drama, criticism, exclusion 